$\xi=-1$

\title{
Single phase PQ theory based control of active power filter for power quality enhancement in DG connected microgrid
}

\author{
M T L Gayatri *, Alivelu M Parimi \\ EEE Department, BITS Pilani-Hyderabad campus, Jawaharnagar, Hyderabad, Telangana, India \\ *Corresponding author E-mail: gayathri2682@yahoo.co.in
}

\begin{abstract}
The number of DG systems like Photovoltaic and Wind Energy Systems are now penetrating more into the conventional power system. In microgrids, loads and generators are in the close vicinity. However, due to the unpredictable nature of non-conventional energy resources like wind and solar with varying loads, it is almost impossible to maintain an accurate power balance between the source and load. Furthermore, to compensate reactive power and harmonics of this AC microgrid and also to maintain a reasonable power quality, it is essential to use a state-of-the-art controller like shunt active power filter (Sh. APF). This research work is an effort in the same direction wherein the actual environmental data like solar irradiation and wind profile have been collected with the help of the weather monitoring system in BITS-Pilani Hyderabad Campus and this data has been used in conceiving and designing an AC microgrid of suitable capacity. The loads included in this system are both harmonic and reactive in nature. Finally, a Sh. APF with an appropriate control scheme has been incorporated in the proposed AC microgrid so that impeccable power quality is maintained at the load end, apart from achieving a good power balance.
\end{abstract}

Keywords: Microgrid; Distributed Generation; Active Power Filter; Power Quality; Reactive Power Compensation.

\section{Introduction}

Electrical practices for the entire power system industry are tremendously changing and involutes new strategies. A microgrid (MG) is a mini power system designed for a low voltage distribution system providing supply for a small island. The power generation is mainly based on renewable energy resources. MG elements include distributed generation (DG) units like PV and wind generators, storage devices, different loads, and controllers. DGs in grid-connected mode using high-speed power electronic equipment has spread-out apprehension about safety conditions of the equipment creating power quality problems. Utilization of these devices in MG imposes serious power quality issues like VAR compensation and the presence of harmonics [1]. Microgrid major power quality problems are mainly classified into voltage quality issues, current quality issues [2]. The distribution system with $3 \mathrm{P}$ $4 \mathrm{~W}$ configuration mainly suffers from the circulating currents due to unbalanced loads. Usage of capacitor banks, application of TSC and TCR devices from classical technology mitigates some of these problems. Conventional passive LC filters can be used to mitigate harmonics and reduce the number of capacitor banks and improves power factor. However, the main drawbacks like bulkiness, resonance, and fixation in the compensation further lead to the development of active power conditioning/filtering technology. The single-phase $\mathrm{p}-\mathrm{q}$ theory for the purpose of active power filtering is proposed in [3] to mitigate current harmonics. Power conditioning with the help of active power filters can easily handle the major power quality issues. Shunt APF using advanced ANN techniques is presented in [4]. Power quality disturbances mitigation using shunt APF is presented in [5]. Control of shunt APF to mitigate current harmonics under distorted supply condition and to achieve IEEE Std.519 condition is mentioned in [6]. Application of customized power devices in a DG system to enhance the power quality is presented in [7]. A single-phase active power filter in a distorted power system environment is used with improved harmonic suppression efficiency with self-tuning filter (STF) algorithm is used in [8]. To enhance the capacity and to ensure operation flexibility by applying multiple and parallel APF units is proposed in [9]. A shunt APF with $3 \mathrm{p} 3 \mathrm{w}$ incorporated with hysteresis current control is used in [10]. From the existing survey, the shunt APF can effectively mitigate many power quality issues and improves the overall performance in the conventional 3p4w distribution system. With this motivation, in this paper, Shunt APF is taken into account to provide power quality compensation in MG distribution system. The major issues such as compensation of reactive power, reduction of current harmonics and neutral current compensation of microgrids are considered as key objectives in this paper. The structure of microgrid, Application of shunt APF in microgrid along with its control technique and design, Simulation results using MATLAB/SIMULINK for mitigation of aforementioned power quality issues in MG are represented section wise. The simulation results validate the effectiveness of the device considered in the system.

\section{Structure of microgrid}

A microgrid using two DG sources shown in the Fig. 1 is developed to deliver a 3-phase distribution voltage of $451 \mathrm{~V}, 50 \mathrm{~Hz}$ at the common $\mathrm{AC}$ bus. Different harmonic, reactive, linear and nonlinear loads are connected to the derived common AC bus. The equivalent parameters are extracted in the simulations from the datasheet [11]. The developed MG containing PV-wind MG generating system is implemented in Simulink /MATLAB environment and is investigated for the real-time data measured at 
Birla Institute of Technology and Science, Hyderabad campus. The modeling and development of the MG are explained in detail in [12]. The I-V and P-V characteristics, a record of solar insolation and wind speed in a day observed are shown in Fig. 2, 3 \& 4 respectively. The variations in the output voltage and active and reactive power flow in each DG with the continuous varying behavior of these parameters is considered. The output voltage and $\mathrm{P}$ responses in case of PV generating system due to the variation in solar irradiation within a range of $600-1000 \mathrm{~W} / \mathrm{m} 2$ for a duration of $1 \mathrm{sec}$ are shown in the Fig. 5. Similarly, the output voltage and $\mathrm{P}, \mathrm{Q}$ responses in case of WECS due to the change in wind speed within a range of $8-12 \mathrm{~m} / \mathrm{s}$ for a duration of $1 \mathrm{sec}$ is shown in the Fig. 6. As the MG delivers different loads with frequent variations i.e., harmonic and reactive, compensation requirement in MG is identified and necessitates compensation as shown in Fig. 1 Hence a device, Shunt APF to provide required compensation is developed to provide power quality enhancement in MG.

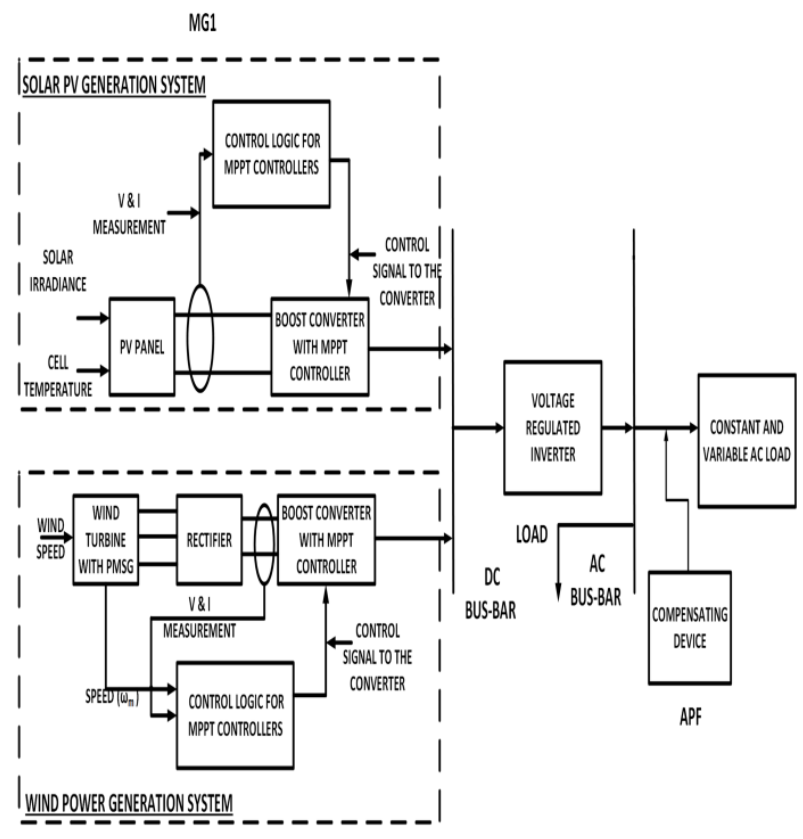

MG2

Fig. 1: Block Diagram of A Microgrid.

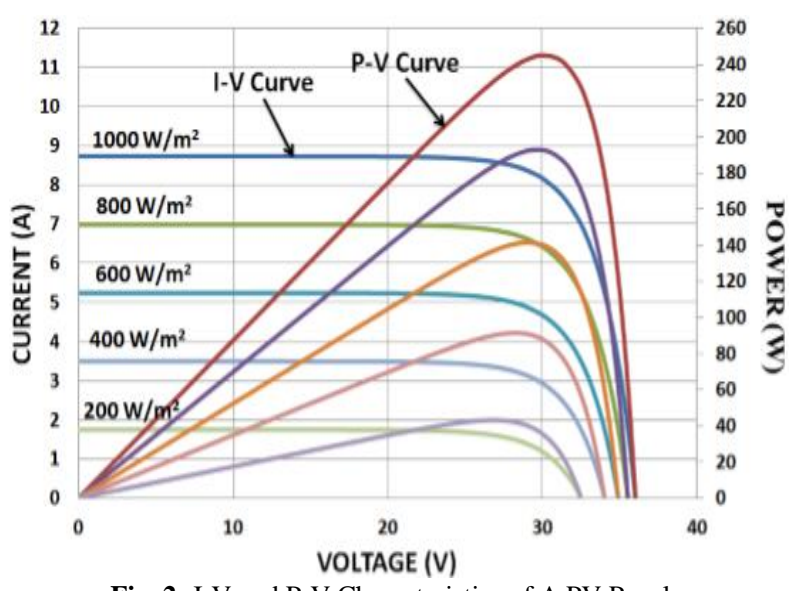

Fig. 2: I-V and P-V Characteristics of A PV Panel.

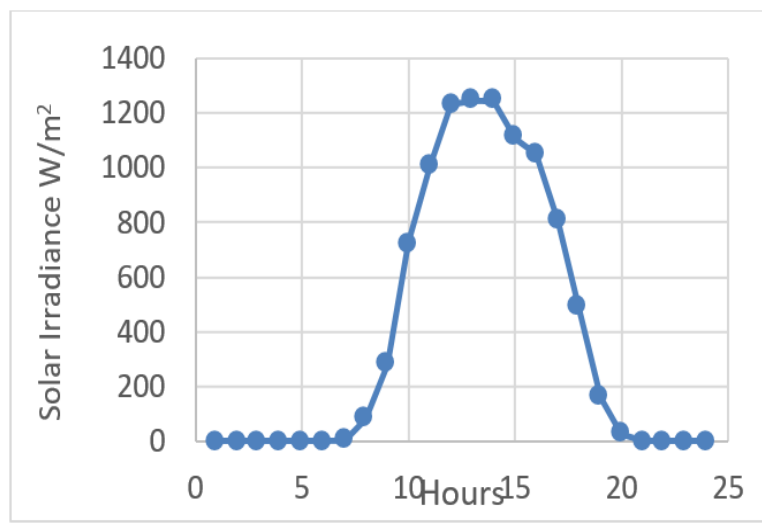

Fig. 3: Variation of Solar Insolation in A Day.

$\sim$ Mvg Wind speed Wind Speed

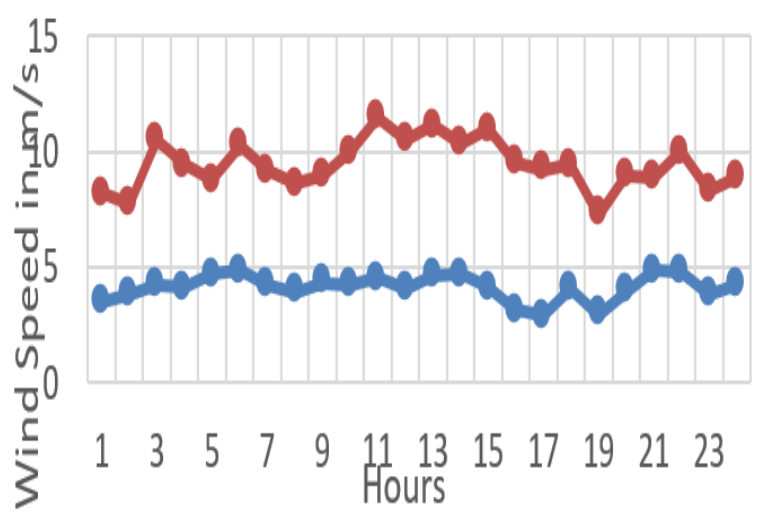

Fig. 4: Variation of Wind Speed in A Day.
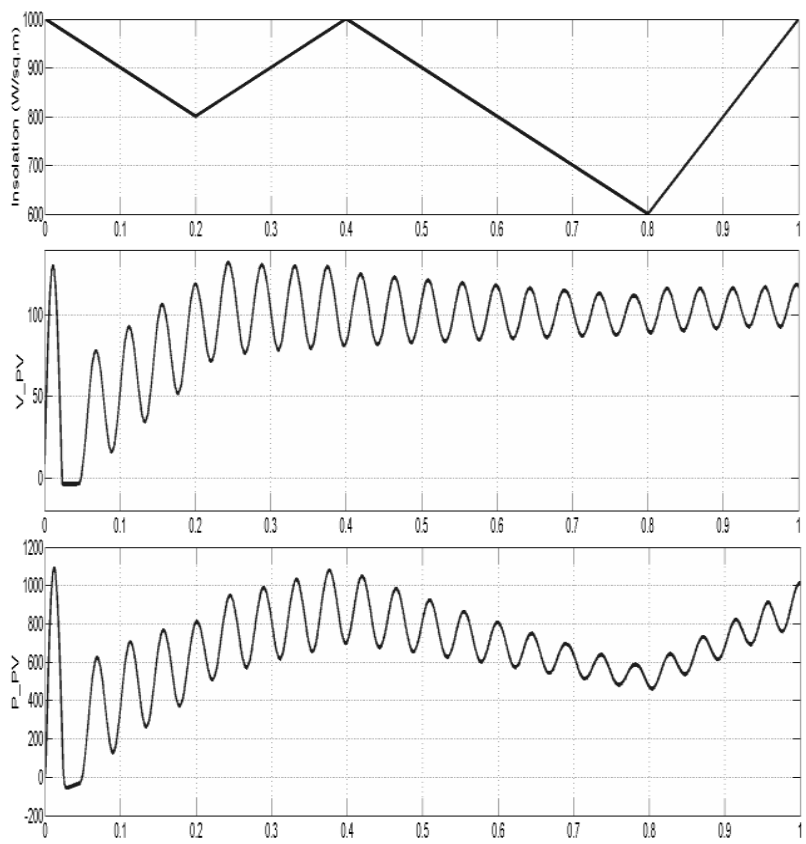

Fig. 5: Voltage \& P Variation Due to Change in Solar Insolation. 

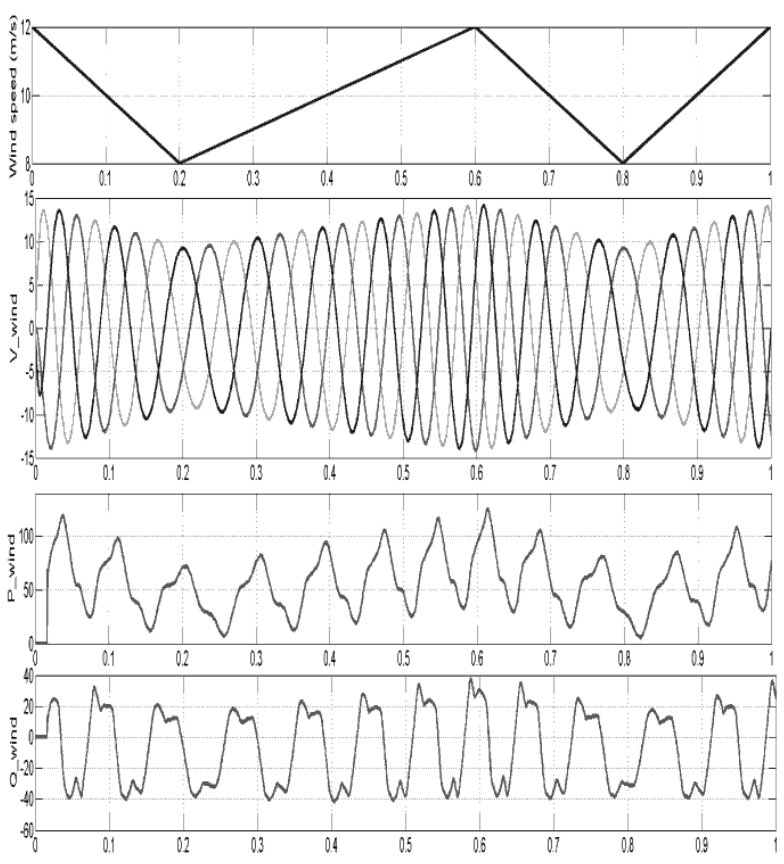

Fig. 6: Voltage, P \& Q Variation Due to Wind Speed in Microgrid.

\section{Design of shunt APF}

Shunt APF mainly functions to compensate current harmonics and ensures to maintain DC link current measured at constant. To achieve this, the DC link current is compared with a constant reference current. The magnitude of reference current is constant and equal to the maximum value of current with harmonics.

\subsection{Current unbalance compensation approach}

In general, the load currents of a $3 \mathrm{P} 4 \mathrm{~W}$ distribution system are unbalanced due to the load connected. To make these currents balanced, a control strategy is proposed modifying single-phase $\mathrm{p}$ q theory. This theory states that a single phase system can be a two-phase system with $90^{\circ}$ lead or $90^{\circ}$ lag. The resultant twophase system representation is in terms of $\alpha-\beta$ coordinates. Based on this, the 3-phase p-q theory can be applied in terms of single phase equivalent approach to determine instantaneous $\mathrm{P} \& \mathrm{Q}$ of the load. To achieve this, all three phase voltages and currents are considered as three individual phase voltages and currents. The actual values are taken as $\alpha-\beta$ quantities with $90^{\circ}$ leading in both load voltages and currents. The complete algorithm for instantaneous reactive power theory based control is shown in Fig. 7. The reference signals for source current are generated as

Three-phase reference supply currents $\left(i^{*} S a, i^{*} S b, i_{S c}^{*}\right)$ are estimated as

$i_{m g, a}^{*}(t)=\frac{v_{\alpha a}(t)}{v_{\alpha a}^{2}+v_{\beta a}^{2}}\left[p_{t}\right]+\frac{v_{\beta a}(t)}{v^{2} \alpha a+v^{2} \beta a}\left[q_{t}\right]$

Similarly, the reference source current for phase-b and phase - c can be estimated as follows:

$$
\begin{aligned}
& i_{m g, b}^{*}(t)=\frac{v_{\alpha b}(t)}{v_{\alpha b}^{2}+v^{2} \beta b}\left[p_{t}\right]+\frac{v_{\beta b}(t)}{v_{\alpha b}^{2}+v^{2} \beta b}\left[q_{t}\right] \\
& i_{m g, c}^{*}(t)=\frac{v_{\alpha c}(t)}{v^{2} \alpha c+v_{\beta c}^{2}}\left[p_{t}\right]+\frac{v_{\beta c}(t)}{v_{\alpha c}^{2}+v^{2} \beta c}\left[q_{t}\right]
\end{aligned}
$$

The estimated reference source current signals $\left(i^{*}{ }_{\mathrm{mg}, \mathrm{a}}, \mathrm{i}^{*} \mathrm{mg}, \mathrm{b},, i^{*} \mathrm{mg,c} \mathrm{c}\right)$ are compared with the measured source current signals $\left(i_{\mathrm{mg}, \mathrm{a}}\right.$, $\left.i_{\mathrm{mg}, \mathrm{b}}, \mathrm{i}_{\mathrm{mg}, \mathrm{c}} \mathrm{c}\right)$. The differences are considered as errors and are amplified further prior fed to a PI current controller. The controller generates the required gating signals for the converter used in shunt APF. The computed and actual current signals are compared and the difference in the values are thus computed. These error values with amplification are processed using a PI controller. A pre-set frequency carrier signal is used for comparison and thus the required gating signals are generated for the VSC used in shunt APF.

\subsection{Neutral current compensation}

The computed balanced source currents from the unbalanced load currents will be generated using the above analysis. The actual neutral current can be calculated by summing all load currents and is given by,

${ }^{i} L, N(t)=i_{L a}{ }^{(t)+i_{L b}}{ }^{(t)+i_{L c}}{ }^{(t)}$

The reference neutral current can be given as,

$$
i_{S h, N}^{*}(t)=-i_{L, N}(t)
$$

By generating the reference currents using the above control approaches, the compensation for harmonics and reactive power is provided in microgrids. The simulation results described in the next section validate the same.

\subsection{Design of shunt APF for power quality compensa- tion}

The design of shunt APF is based on the following equations. The load current drawn by non-linear diode bridge converter $=$ IDC.

$V_{D C, A P F}=\frac{2 \sqrt{2} V_{M G, a}}{m_{\alpha}}$

Where $m_{a}$ is modulation index.

The minimum DC voltage required is

$V_{D C, \min }=\frac{\sqrt{3} * \sqrt{2} * V_{M G, a}}{0.87}$

The interfacing inductance of the shunt APF is

$L_{f, \text { interface }}=\frac{\sqrt{3} m_{a} V_{D C, A P F}}{2 * 6 * a * f_{s} * I_{f, \text { difference }}}$

The DC link capacitance of the shunt APF is

$$
\begin{aligned}
& C_{D C}= \\
& \frac{2 * E_{\text {diff }}}{\left.{\left(v^{2} D C, A P F\right.}^{2}{ }^{2} D C \min , A P F\right)}=\frac{3 * V_{f} * I_{f} * t}{\left(v^{2} D C, A P F-v^{2} D C \min , A P F\right)}
\end{aligned}
$$

Based on the filter and DC link parameters calculated, Shunt APF has been designed and the next section presents the simulation results that are obtained. 
Table 1: Design Parameters of Shunt APF

\begin{tabular}{lll}
\hline Electrical Parameters & Notation & Value in Units \\
\hline Microgrid reference voltage & $\mathrm{V}_{\mathrm{s}}$ or $\mathrm{V}_{\mathrm{mg}}$ & $415 \mathrm{~V}$ \\
Fundamental frequency & $\mathrm{f}$ & $50 \mathrm{~Hz}$ \\
Source Inductance & $\mathrm{L}_{\mathrm{S}}$ & $0.5 \mathrm{mH}$ \\
Reference Dc bus voltage & $\mathrm{V}_{\mathrm{DC}}$ & $750 \mathrm{~V} \mathrm{DC}$ \\
Bus capacitor & $\mathrm{C}_{\mathrm{DC}}$ & $2000 \mu \mathrm{F}$ \\
Inverter coupling & $\mathrm{L}_{\mathrm{s}}$ & $5.583 \mathrm{mH}$ \\
\hline
\end{tabular}

\section{Results}

A microgrid in Fig. 1 is developed and simulated based on equation-based modeling described in section 2 and delivers a distribution 3-phase voltage of $415 \mathrm{~V}, 50 \mathrm{~Hz}$ as shown in Fig. 1. The output voltage is the reference source voltage of the developed MG From this reference, the distribution system is connected. To this modeled MG, different loads are connected. The different operating conditions like switching of loads creating voltage problems, current harmonics, and connection of various reactive loads into the system are simulated and analyzed in the MG considered. Later the modeled shunt APF is incorporated into the same MG to mitigate all the aforementioned power quality issues. A supply sag and swell with $21 \%$ of output for a period of $0.4 \mathrm{sec}$ (sag from 0.05 to $0.15 \mathrm{sec}$, swell from 0.25 to $0.35 \mathrm{sec}$ ) as shown in Fig. 8(b). The reference voltage is indicated in Fig. 8(a) for comparison. For clear analysis, only the phase 'a' components are considered. Fig. 8(c), (d), represents sag voltage and currents in phase 'a', Fig. 8 (e), (f) represents injected voltage and current of phase 'a' by series and shunt APFs, Fig. 8 (g), (h) represents the mitigated load voltage and current of phase ' $a$ ' for supply sag using shunt APF. Fig. 8 (i) shows the recovered 3-phase output of MG load voltage using shunt APF against the supply sag.

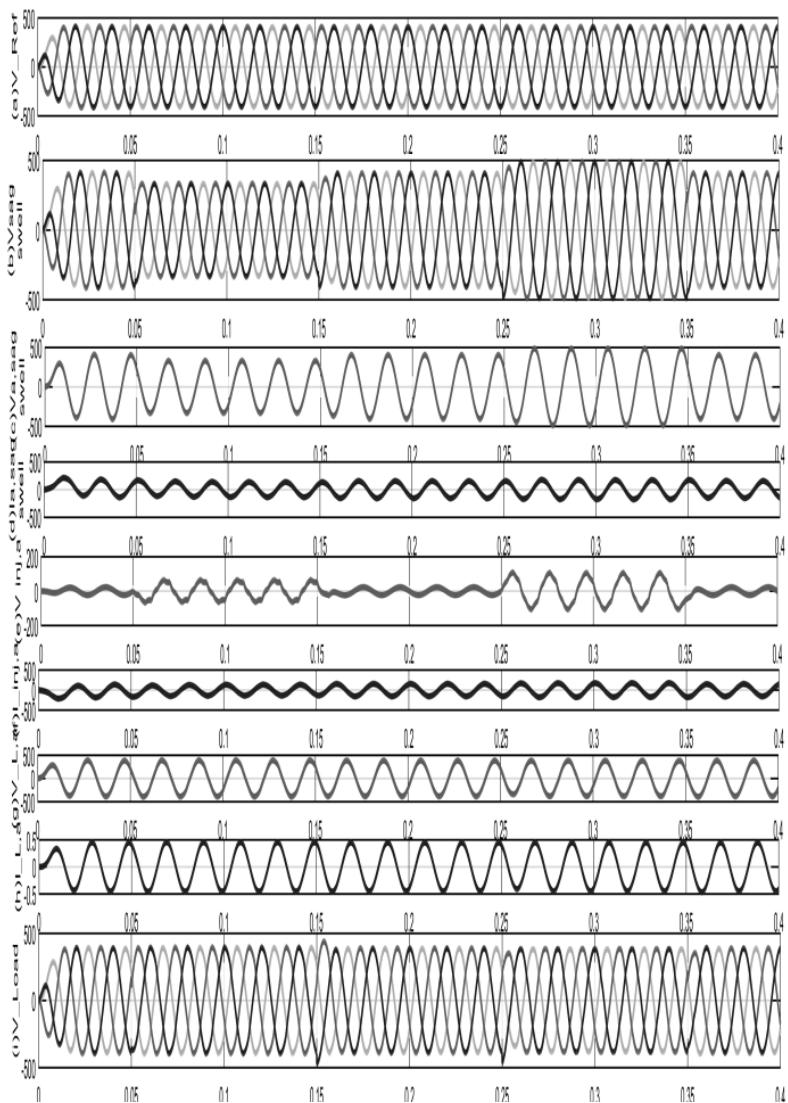

Fig. 8: Mitigation of Simultaneous Sag/Swell in Supply Voltage in MG.

It is found that the shunt APF is able to compensate this abnormal condition very effectively without any reluctance. The harmonic compensation is provided by using the shunt APF control and the results in terms of \% THD are shown in Fig. 9 and Fig. 10. A nonlinear load that creates harmonics with $150.84 \%$ THD in source current is connected. When shunt APF is connected, the \% THD is reduced to a value of 49.69 with a THD of $0.99 \%$ in load voltage as shown in Fig. 11. The distorted and compensated source current waveforms are shown in Fig. 12. Similarly, neutral current with and without compensation is represented in Fig. 13. The DC link voltage and current variation are shown in Fig. 14 and Fig. 15. From the above results, the effectiveness of shunt APF in providing harmonic and reactive compensation is verified.

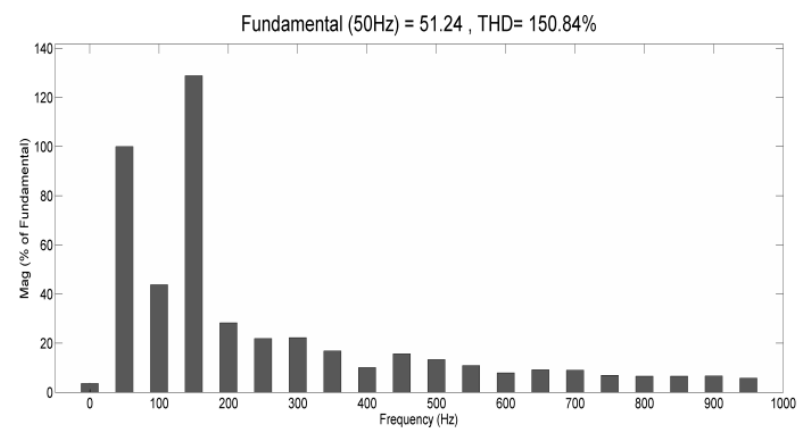

Fig. 9: Harmonics in Source Current.

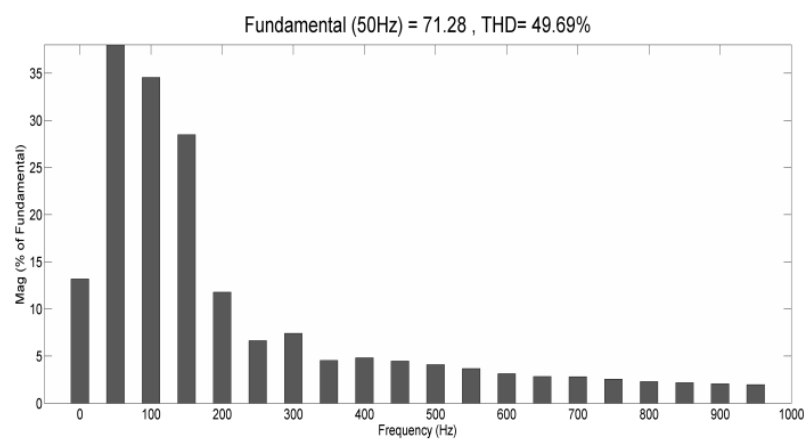

Fig. 10: Compensated Source Current.

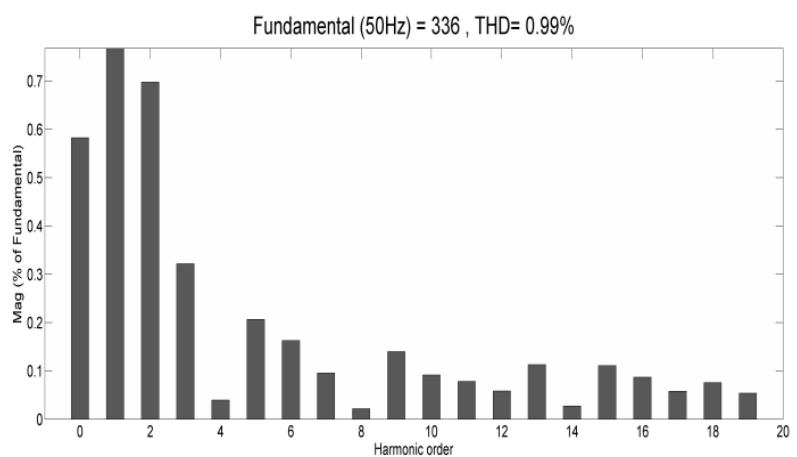

Fig. 11: Load Voltage.

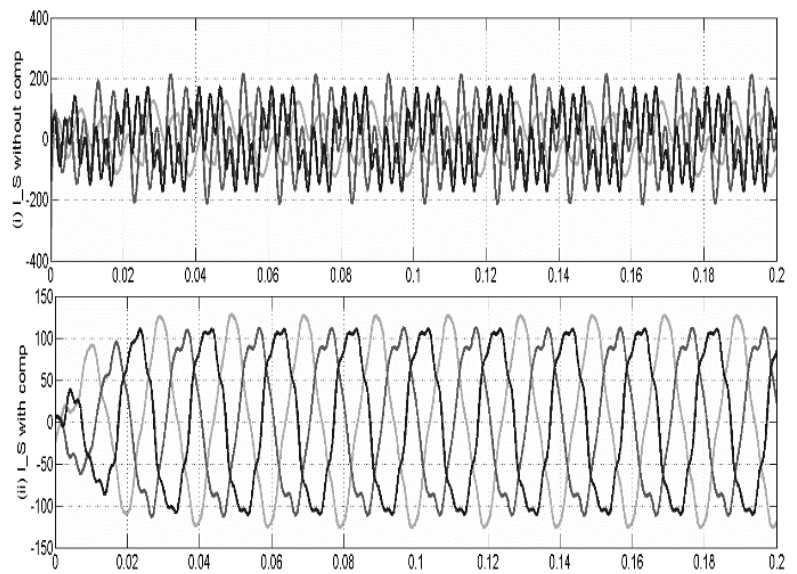

Fig. 12: Source Current with and Without Compensation. 


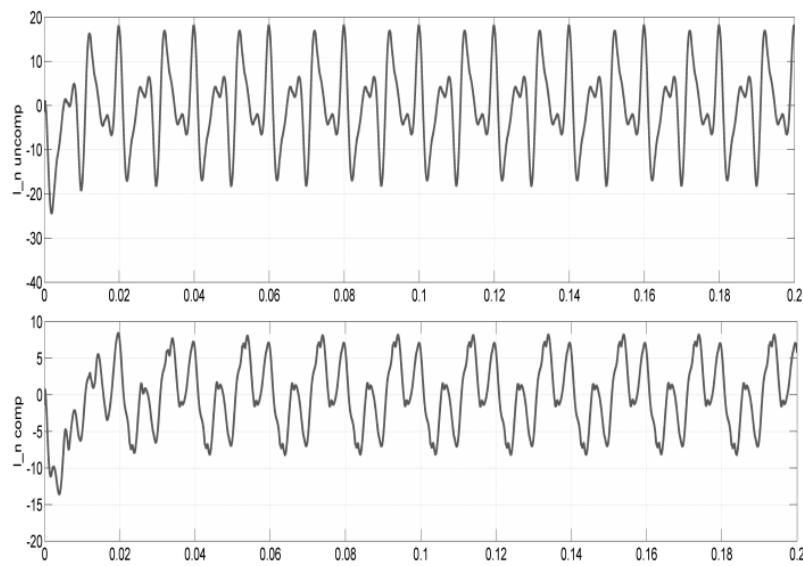

Fig. 13: Neutral Current with and Without Compensation.

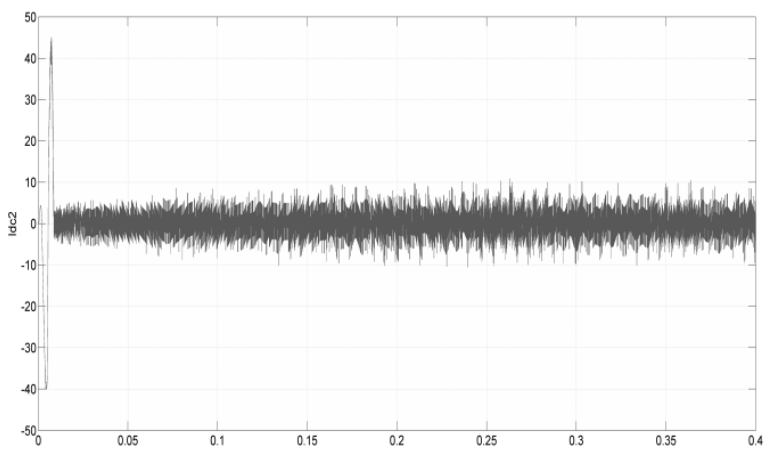

Fig. 14: DC Link Current.

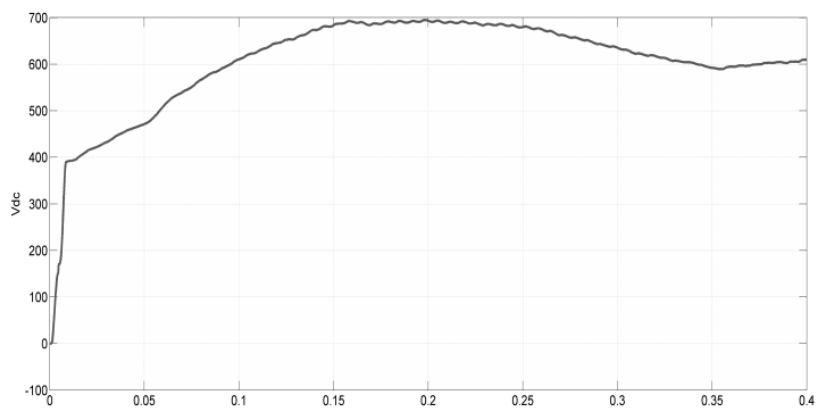

Fig. 15: DC Link Voltage Control.

\section{Conclusion}

A distribution generation based microgrid consisting of a WECS, solar PV, and stand-alone AC loads has been considered in this paper to analyze its performance under various operating conditions. It is found that when the wind velocities are changing or partial shadowing occurs, it would cause huge disturbances in the sources, apart from load variations imparting their own perturbances in the form of power quality disturbances. Similarly, the connection of non-linear loads in the form of power electronic equipment pollutes the MG power quality with harmonics. To overcome these problems, a shunt APF has been systematically designed and a novel control strategy has been proposed to compensate for reactive and harmonic components. The shunt APF with the modified PQ control has been able to provide power quality compensation thus keeping current and voltage quality at the supply side/load and within the norms.

\section{References}

[1] Hingorani, N.G.: Introducing custom power. vol .32, pp. 41-48 IEEE Spectrum, (1995) https://doi.org/10.1109/6.387140.

[2] Hingorani, N.G.: High power electronics and flexible AC transmission system. J. IEEE Power Engg Review, 8, 3-4, (1988). https://doi.org/10.1109/MPER.1988.590799.
[3] Khadkikar, V., Chandra, A., Singh, B. N.: Generalized single-phase p-q theory for active power filtering: simulation and DSP-based experimental investigation. J. IET Power Ele, 2, 67-78, (2009) https://doi.org/10.1049/iet-pel:20070375.

[4] Qasim, M., Khadkikar, V.: Application of artificial neural networks for shunt active power filter control. J. IEEE Transl. Industrial Informatics, $10, \quad 1765-1774$,

(2014) https://doi.org/10.1109/TII.2014.2322580.

[5] Khadkikar, V., Chandra: An independent control approach for three-phase fourwire shunt active filter based on three h-bridge topology under unbalanced load conditions. In: IEEE Power Electronics Specialists Conference, pp. 4643-4649. IEEE Press, New York (2008).

[6] Kanjiya, P., Khadkikar, V.,Zeineldin, H.H.: Optimal control of shunt active power filter to meet ieee std. 519 current harmonic constraints under non ideal supply condition. J. IEEE Transl. Industrial Electronics, 62, 724-734, (2015). https://doi.org/10.1109/TIE.2014.2341559.

[7] Khadem, S.K., Basu, M., Conlon, M.F.: Harmonic power compensation capacity of shunt active power filter and its relationship with design parameters. J. IET Power Ele, 7, 418-430, (2014) https://doi.org/10.1049/iet-pel.2013.0098.

[8] Biricik, S., Redif, S., Khadem, S.K., Basu, M: Control of the single phase parallel active filter under weak grid voltages. In: IEEE 5th International Symposium on Power Electronics for Distributed Generation Systems, pp. 1-5. Galway, Ireland (2014). https://doi.org/10.1109/PEDG.2014.6878675.

[9] Khadem, S.K., Basu, M., Conlon, M.F.: Reduction of circulating current flow in parallel operation of apf based on hysteresis current control. In: Power Engineering Conference (PEC). pp. 1-6. 48th international universities

(2013). https://doi.org/10.1109/UPEC.2013.6715013.

[10] Khadem, S.K., Basu, M., Kerrigan, R., Basu, B: Placement of statcom to improve the power quality of a DG integrated building energy system in virtual environment. In: IEEE 23rd International Symposium on Industrial Electronics, pp. 2676-2681. IEEE Press, New York (2014). https://doi.org/10.1109/ISIE.2014.6865043.

[11] Gayatri, M.T.L., Parimi, A.M., Pavan kumar A.V.: Application of Dynamic Voltage Restorer in microgrid for voltage sag/swell mitigation. In: IEEE Power, Communication and Information Technology Conference, pp. 750-755. Bhubaneswar, India (2015).

[12] Gayatri, M.T.L., Parimi, A.M.: Mitigation of supply \& load side disturbances in an AC microgrid using UPQC. In: IEEE 6th International Symposium on Power Systems, pp. 1-6. Delhi, India (2016). https://doi.org/10.1109/ICPES.2016.7584116. 